\title{
Lattice Boltzmann simulations for transition from dropwise to filmwise condensation on hydrophobic surfaces with hydrophilic spots
}

\author{
Xiaoping Li, Ping Cheng*
}

\begin{abstract}
:
Transition from dropwise to filmwise condensation of a dry saturated vapor on downward-facing smooth subcooled horizontal hydrophobic walls with hydrophilic spots is simulated numerically using the newly developed phase-change lattice Boltzmann method. Dynamic behaviors including growth, coalescence and departure of condensate droplets from cooler surface are investigated. Effects of wall subcooling and wettability of the cooler surface on droplet departure diameter, average cycle time and nucleation time are presented. At small wall subcoolings, droplets are formed on hydrophilic spots of the hydrophobic surface. With increasing wall subcoolings, coalescence of droplets and their subsequent departure are observed. Further increase of the wall subcooling leads to transition from dropwise condensation to filmwise condensation mode, and droplets fall down from the subcooled surface at locations according to Taylor's unstable wavelength. The dropwise condensation curve in terms of average heat flux versus wall subcooling from droplet nucleation to peak dropwise condensation heat flux and its subsequent transition to filmwise condensation is obtained numerically for the first time. It is found that the location where droplet or liquid film in contact with the downwardfacing surface has a high local heat flux, especially around the triple-phase contact line. The degree of wall subcooling corresponding to peak dropwise condensation heat flux increases with the increasing pitch distance between hydrophilic spots. The cooler's hydrophobic surface with a smaller contact angle has a lower peak dropwise condensation heat flux which occurs at a smaller degree of wall subcooling. During transition from dropwise to filmwise condensation, there is a graduate reduction in wall heat flux under constant wall temperature conditions, and a sudden drop in the average wall temperature of the subcooled surface under constant wall heat flux conditions.
\end{abstract}

Keywords: condensation, Lattice Boltzmann method, transition, curve

\section{Nomenclature}

$c_{v}$

specific heat at constant volume $\left(\mathrm{J} \mathrm{kg}^{-1} \mathrm{~K}^{-1}\right)$ 


\begin{tabular}{|c|c|}
\hline$c_{s}$ & lattice sound speed $(\mathrm{m} / \mathrm{s})$ \\
\hline$d$ & pitch distances (m) \\
\hline$D^{*}$ & dimensionless droplet diameter \\
\hline $\mathbf{F}$ & total force $(\mathrm{N})$ \\
\hline $\mathbf{F}_{\mathrm{g}}$ & gravitational force $(\mathrm{N})$ \\
\hline $\mathbf{F}_{\text {int }}$ & inter-particle interaction force $(\mathrm{N})$ \\
\hline $\mathbf{F}_{\mathrm{s}}$ & fluid-solid interaction force $(\mathrm{N})$ \\
\hline g & gravitational acceleration $\left(\mathrm{m} / \mathrm{s}^{2}\right)$ \\
\hline$h_{f g}$ & latent heat $(\mathrm{J} / \mathrm{kg})$ \\
\hline$H$ & thickness of cooler (m) \\
\hline$J a$ & Jacob number \\
\hline$l_{0}$ & characteristic length (m) \\
\hline$L_{c}$ & length of cooler (m) \\
\hline$L_{s}$ & length of hydrophilic spots (m) \\
\hline$q^{*}$ & dimensionless local heat flux \\
\hline$q_{\mathrm{ave}}{ }^{*}$ & dimensionless space- and time-averaged heat flux \\
\hline$t^{*}$ & dimensionless time \\
\hline$t_{\mathrm{c}} *$ & dimensionless average cycle time \\
\hline$t_{\mathrm{n}} *$ & dimensionless nucleation time \\
\hline$t_{0}$ & characteristic time (s) \\
\hline$u_{0}$ & characteristic velocity $(\mathrm{m} / \mathrm{s})$ \\
\hline $\mathbf{u}, \mathbf{U}$ & velocity vector $(\mathrm{m} / \mathrm{s})$ \\
\hline
\end{tabular}

Greek symbol

$\begin{array}{ll}\beta & \text { weighting factor } \\ \rho & \text { density }\left(\mathrm{kg} / \mathrm{m}^{3}\right) \\ \theta & \text { static contact angle }\left(^{\circ}\right) \\ \psi & \text { effective mass } \\ \omega_{i} & \text { weight coefficient }\end{array}$




$\begin{array}{ll}\lambda & \text { thermal conductivity of the cooler }\left(\mathrm{W} \mathrm{m}^{-1} \mathrm{~K}^{-1}\right) \\ \lambda_{\mathrm{D}} & \text { "most dangerous" Taylor wavelength }(\mathrm{m}) \\ \Phi & \text { source term } \\ \tau & \text { relaxation time } \\ \sigma & \text { surface tension }(\mathrm{N} / \mathrm{m}) \\ \text { Subscripts or Superscripts } \\ \text { ave } \\ \text { cr } & \text { average } \\ \text { eq } & \text { critical } \\ 1 & \text { equilibrium } \\ \text { S } & \text { liquid } \\ \text { sat } & \text { spot } \\ \text { v } & \text { saturation } \\ \text { W } & \text { vapor } \\ \end{array}$

\section{Introduction}

Condensation heat transfer occurs frequently in natural environment as well as in many engineering systems. It is a subfield of heat transfer that has been the subject of intensive studies during the past century [1]. It is known that condensation can be classified into two categories: dropwise condensation and filmwise condensation. Nusselt [2] published the first analytical solution on film condensation on a vertical subcooled flat plat in 1916 while LeFevre and Rose [3] published the first model on dropwise condensation on a horizontal subcooled surface in 1966. In the following year, Rose [4] suggested that transition from dropwise condensation to filmwise condensation occurred at a sufficiently high condensation heat flux when the rate at which new surface was exposed by droplet coalescences (which remains to be constant) was smaller than the rate of droplet formation on the surface. Subsequently, Takeyama et al. [5] as well as Tanasawa et al. [6] carried out experiments to study the transition from dropwise to filmwise condensation of steam on a hydrophobic surface, and obtained the peak condensation heat flux at atmospheric pressure. Stylianou and Rose [7] discussed condensation of ethylene glycol on PTFE coated surfaces and copper surfaces promoted with oleic acid, and they reported similar condensation transition phenomenon. Utaka et al. [8-10] carried out experiments to obtain dropwise condensation curves on a hydrophobic surface which described transition from dropwise to filmwise condensation under constant wall temperature conditions. Ma et 
al. [11] introduced the concept of surface free energy difference between condensate and ultra thin liquid film to explain the transition of condensation modes. They found that transition from dropwise condensation to filmwise condensation took place when the equivalent surface free energy difference decreased.

In recent years, renewed interest is given to the study of surface's wettability on condensation heat transfer [12-14]. Mixed wettability surfaces have been proposed to enhance condensation heat transfer [15-20]. Chatterjee et al. [15] conducted an experiment to study condensation on surfaces with patterns of distinct hydrophilic and hydrophobic regions (island-patterns and tree-patterns), and observed better condensation heat transfer performance than those on uniform hydrophobic surfaces. Ghosh et al. [16] and Mahapatra et al. [17] designed bioinspired wettability patterned superhydrophilic tracks on a hydrophilic background. These mixed wettability surfaces could facilitate capillary-driven condensate drainage and enhanced dropwise condensation heat transfer by reducing the size of departing droplets on hydrophilic regions. Peng et al. [18] studied condensation heat transfer on vertically patterned hydrophobic-hydrophilic hybrid surfaces experimentally, and they obtained condensation heat transfer by a weighted average of dropwise and filmwise condensation models [19]. They concluded that there existed an optimal length of the hydrophobic strips while the heat transfer coefficient decreased with increase of hydrophilic strips length. Lee et al. [20] carried out condensation experiments on surfaces with superhydrophobicity-based interlaced wettability under horizontal and vertical surface orientations. They observed opposite heat transfer trends under different surface orientations.

Most of previous numerical simulations on condensation heat transfer have been carried out based on volume of fluid (VOF) methods [21-23]. Aghanajafi and Hesampour [21] studied turbulent film condensation on a horizontal elliptical tube by VOF method. Da Riva and Del Col [22] presented a three-dimensional VOF simulation to investigate the condensation of $\mathrm{R} 134 \mathrm{a}$ in horizontal circular minichannels. They concluded that the characteristics of condensation were dominated by gravity while the effect of surface tension was negligible. Liu et al. [23] developed a computational model to study condensation heat transfer between vertical parallel plates using VOF method to track the vapor-liquid interface. However, it is difficult to capture the interface during phase change numerically based on NavierStokes equations, especially when the evolution of interface is rapid. Most recently, Gong and Cheng [24, 25] proposed an improved phase-change Lattice Boltzmann method and simulated bubble nucleation, growth and departure on a heater surface. With this newly developed LBM model, they obtained saturated boiling curves on hydrophilic and hydrophobic heater surfaces for the first time [26]. Liu and Cheng [27] applied this newly developed method to simulate steady laminar film condensation on a vertical hydrophilic subcooled flat plate and reported that their simulated results were in good agreement with the classical Nusselt model [2]. In another paper [28], they used the same method to simulate dropwise condensation of saturated vapor on a subcooled cold spot of a vertical hydrophobic flat plate.

In this paper, condensation on downward-facing subcooled horizontal hydrophobic surfaces with hydrophilic spots is simulated numerically based on GongCheng phase-change LB model $[24,25]$. The droplet departure diameter, average 
cycle time, temperature and heat flux distributions on a small hydrophobic cooler surface with a single hydrophilic spot at small wall subcoolings are investigated. Droplets falling patterns from a subcooled downward-facing horizontal hydrophobic surface with multiple hydrophilic spots at small wall subcoolings as well as during filmwise condensation at large wall subcooling are presented. Dropwise condensation curves in terms of dimensionless averaged heat flux versus Jacob number (from droplet nucleation to peak dropwise condensation heat flux, and its subsequent transition to filmwise condensation) on hydrophobic surfaces with multiple hydrophilic spots are numerically obtained under different wall subcooling conditions.

\section{Description of the simulation model}

In this section, we will describe the Gong-Cheng phase-change LB model used in our simulation, which includes a pseudo-potential lattice Boltzmann multiphase flow model [29] and an energy equation model [24].

\subsection{Pseudo-potential lattice Boltzmann multiphase flow model}

In the lattice Boltzmann method, a discrete distribution function $f_{i}$ is introduced to represent the density of fluid. The evolution equation of the density distribution function satisfies the following Lattice Boltzmann equation:

$$
f_{i}\left(\mathbf{x}+\mathbf{e}_{i} \delta t, t+\delta t\right)-f_{i}(\mathbf{x}, t)=-\frac{1}{\tau}\left(f_{i}(\mathbf{x}, t)-f_{i}^{e q}(\mathbf{x}, t)\right)+\Delta f_{i}(\mathbf{x}, t)
$$

where $\mathbf{x}$ is position in space, $t$ is time, $\delta t$ is time step, $\mathbf{e}_{i}$ is discrete particle velocity in $i^{\text {th }}$ direction, $\tau$ is relaxation time. $f_{i}(\mathbf{x}, t)$ represents the particle distribution function and $f_{i}^{e q}(\mathbf{x}, t)$ is the corresponding equilibrium distribution function, given as:

$$
f_{i}^{e q}(\mathbf{x}, t)=\omega_{i} \rho\left[1+\frac{\mathbf{e}_{i} \cdot \mathbf{u}}{c_{s}^{2}}+\frac{\left(\mathbf{e}_{i} \cdot \mathbf{u}\right)^{2}}{2 c_{s}^{4}}-\frac{\mathbf{u}^{2}}{2 c_{s}^{2}}\right]
$$

where $\omega_{i}$ are weighting coefficients, $c_{\mathrm{s}}$ is the lattice sound speed.

The two-dimension nine-velocity scheme (D2Q9) is adopted in our simulation. In D2Q9 model, $c_{\mathrm{s}}^{2}=c^{2} / 3$, where $c$ is the lattice speed calculated by $c=\delta \mathrm{x} / \delta t$. The weighting coefficient $\omega_{i}$ are given as: $\omega_{0}=4 / 9, \omega_{1-4}=1 / 9, \omega_{5-8}=1 / 36$. The discrete particle velocity $\mathbf{e}_{i}$ are given as:

$$
\mathbf{e}_{i}=\left\{\begin{array}{lc}
(0,0), & i=0 \\
( \pm 1,0) c,(0, \pm 1) c, & i=1-4 \\
( \pm 1, \pm 1) c, & i=5-9
\end{array}\right.
$$

The macroscopic density $\rho$ and velocity $\mathbf{u}$ can be obtained from:

$$
\begin{gathered}
\rho=\sum_{i} f_{i} \\
\mathbf{u}=\frac{1}{\rho} \sum_{i} f_{i} \mathbf{e}_{i}
\end{gathered}
$$

The relaxation time is related to the kinematic viscosity, calculated by:

$$
\tau=\frac{v}{c_{s}^{2} \delta t}+0.5
$$


There are three commonly used schemes to implement force into the lattice Boltzmann method, including the Shan-Chen's velocity shifting method [30], the Kupershtokh et al.'s exact difference method (EDM) [31] and Guo et al.'s force method [32]. In this paper, we choose the EDM method [31] due to its better accuracy and independence of relaxation time [29]. According to EDM method, the force term is written as:

$$
\Delta f_{i}(\mathbf{x}, t)=f_{i}^{e q}(\rho(\mathbf{x}, t), \mathbf{u}+\Delta \mathbf{u})-f_{i}^{e q}(\rho(\mathbf{x}, t), \mathbf{u})
$$

where $\Delta \mathbf{u}$ is the change of velocity due to the total force $\mathbf{F}$ during time step $\delta t$, given by:

$$
\Delta \mathbf{u}=\frac{\mathbf{F} \delta t}{\rho}
$$

It is worth mentioning that the $\mathbf{u}$ calculated by Eq.(5) is not the real physical velocity. The real velocity of fluid is described as:

$$
\mathbf{U}=\mathbf{u}+\frac{\mathbf{F} \delta t}{2 \rho}
$$

The calculation of total force $\mathbf{F}$ is one of the most important steps. The total force $\mathbf{F}$ consists of three parts, including the inter-particle interaction force $\mathbf{F}_{\text {int }}$, the fluid-solid interaction force $\mathbf{F}_{\mathrm{s}}$, and the gravitational force $\mathbf{F}_{\mathrm{g}}$, which can be written as:

$$
\mathbf{F}=\mathbf{F}_{\text {int }}+\mathbf{F}_{s}+\mathbf{F}_{g}
$$

According to Gong and Cheng's method [29], the inter-particle interaction force is given by:

$$
\mathbf{F}_{\mathrm{int}}=-\beta \psi(\mathbf{x}) \sum_{i} \mathrm{G}\left(\mathbf{x}+\mathbf{e}_{i} \delta t\right) \psi\left(\mathbf{x}+\mathbf{e}_{i} \delta t\right) \mathbf{e}_{i}-\frac{1-\beta}{2} \sum_{i} \mathrm{G}\left(\mathbf{x}+\mathbf{e}_{i} \delta t\right) \psi^{2}\left(\mathbf{x}+\mathbf{e}_{i} \delta t\right) \mathbf{e}_{i}
$$

where $\beta$ is the weighting factor depending on the particular equation of state [29], and $\mathrm{G}\left(\mathbf{x}+\mathbf{e}_{i}\right)$ represent interaction strength, given by:

$$
\mathrm{G}\left(\mathbf{x}+\mathbf{e}_{i} \delta t\right)=\left\{\begin{array}{cc}
g_{1}, & \left|\mathbf{e}_{i}\right|=1 \\
g_{2}, & \left|\mathbf{e}_{i}\right|=\sqrt{2} \\
0, & \text { otherwise }
\end{array}\right.
$$

$\psi(\mathbf{x})$ is the effective mass which depends on the equation of state. It is given by:

$$
\psi(\mathbf{x})=\sqrt{\frac{2\left(p-\rho c_{s}^{2}\right)}{c_{0} g}}
$$

where in D2Q9, $g_{1}=2 g, g_{2}=g / 2, c_{0}=6$ and we choose the Peng-Robinson equation of state in this work.

The fluid-solid interaction force is calculated as below:

$$
\mathbf{F}_{s}=-\mathrm{G}_{s} \psi(\mathbf{x}) \sum_{i} \omega_{i} s\left(\mathbf{x}+\mathbf{e}_{i} \delta t\right) \mathbf{e}_{i}
$$

where $\mathrm{G}_{s}$ is the fluid-solid interaction strength, which is applied to change the contact angle of the surface, $s\left(\mathbf{x}+\mathbf{e}_{i} \delta t\right)$ is an indicator function with $s=1$ for solid and $s=0$ for fluid.

The gravitational force is given by: 


$$
\mathbf{F}_{g}=\left(\rho(\mathbf{x})-\rho_{v}\right) \mathbf{g}
$$

where $\boldsymbol{g}$ is gravitational acceleration, and the liquid-vapor interface is decided by $\rho=\left(\rho_{l}+\rho_{v}\right) / 2$.

\subsection{Energy equation model}

The evolution equation of the temperature distribution function is given by [24]:

$$
g_{i}\left(\mathbf{x}+\mathbf{e}_{i} \delta t, t+\delta t\right)-g_{i}(\mathbf{x}, t)=-\frac{1}{\tau_{T}}\left(g_{i}(\mathbf{x}, t)-g_{i}^{e q}(\mathbf{x}, t)\right)+\delta t \omega_{i} \phi
$$

where $\tau_{T}$ is the relaxation time for temperature which is given as $\tau_{T}=\frac{\chi}{c_{s}^{2} \delta t}+0.5$, and $g_{i}{ }^{e q}(\mathbf{x}, t)$ is the temperature equilibrium distribution function given by:

$$
g_{i}^{e q}(\mathbf{x}, t)=\omega_{i} T\left[1+\frac{\mathbf{e}_{i} \cdot \mathbf{U}}{c_{s}^{2}}+\frac{\left(\mathbf{e}_{i} \cdot \mathbf{U}\right)^{2}}{2 c_{s}^{4}}-\frac{\mathbf{U}^{2}}{2 c_{s}^{2}}\right]
$$

where the temperature can be calculated as:

$$
T=\sum_{i} g_{i}
$$

The source term for phase change process is given by Gong and Cheng [24] as:

$$
\phi=T\left[1-\frac{1}{\rho c_{v}}\left(\frac{\partial p}{\partial T}\right)_{\rho}\right] \nabla \cdot U
$$

\section{Results and discussion}

In this section, we will simulate condensation process on a downward-facing smooth horizontal subcooled surface numerically based on Gong and Cheng's phase change LB model discussed in the previous section. The simulation results for condensation on a downward facing horizontal hydrophilic plate at a subcooled temperature will be presented in the following paragraphs.

\subsection{Computation domain and boundary conditions}

The schematic of the computational domain is shown in Fig.1. In this simulation, the size of $2 \mathrm{D}$ computational domain is taken as $L_{x} \times L_{y}=1000 \times 1000$ lattice units $(l u)$, and the space below the downward facing surface is occupied initially by a dry saturated steam at $T_{\text {sat }}$. As shown, a cooler (indicated by a gray color) with a length of $L_{c}$ and a thickness of $H$ is placed at the center of downward facing surface while other part of the plate is made of thermal insulation material (indicated by a blue color). The top cooler surface at $y=0$ is maintained either at constant wall temperature ( $\left.T=T_{\mathrm{w}}<T_{\mathrm{sat}}\right)$ or at constant heat flux conditions. 2D heat conduction in the cooler is taken into consideration in this paper. The half-way bounce back boundary condition for density is imposed on the bottom cooler surface at $y=H$ while periodic conditions are specified on the right- and left-hand side of the computation domain and the extrapolation boundary condition [33] is adopted at the bottom boundary of the computation domain. 


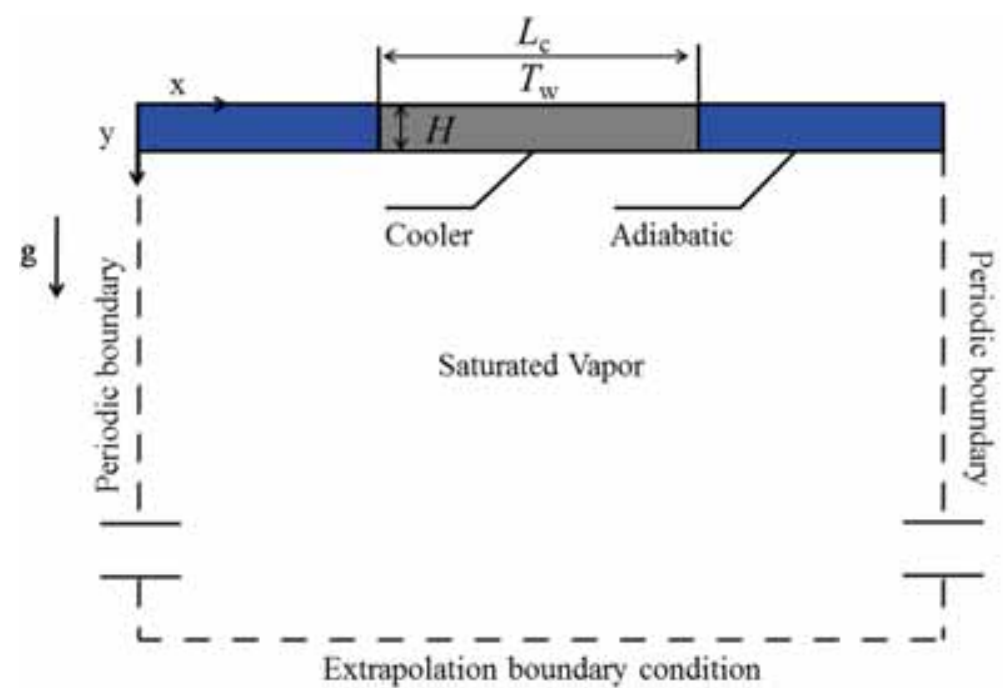

Fig.1. Schematic of the computation domain.

In this paper, the capillary length is chosen as the characteristic length, which is defined as the ratio of surface tension and buoyancy as [34]:

$$
l_{0}=\sqrt{\frac{\sigma}{g\left(\rho_{l}-\rho_{v}\right)}}
$$

and the characteristic velocity and characteristic time can be calculated from

$$
t_{0}=\sqrt{l_{0} / \mathrm{g}}
$$

The degree of wall subcooling is nondimensionalized and described by the Jacob number given by:

$$
J a=\frac{c_{v}\left(T_{s}-T_{w}\right)}{h_{f g}}
$$

where $c_{v}$ is specific heat and $h_{f g}$ is latent heat.

To ensure stable numerical results, we choose $T_{\mathrm{sat}}=0.9 T_{\mathrm{cr}}$ in this paper. Note that in our simulation, all the variables are represented in lattice units and the principal of reduced properties are used to relate them to physical properties. The relationships between lattice units and the real units are as follows:

$$
T^{*}=\frac{T^{l u}}{T_{c r}^{l u}}=\frac{T^{\text {real }}}{T_{c r}^{\text {real }}}, \quad l^{*}=\frac{l^{l u}}{l_{0}^{l u}}=\frac{l^{\text {real }}}{l_{0}^{\text {real }}}, \quad t^{*}=\frac{t^{l u}}{t_{0}^{l u}}=\frac{t^{\text {real }}}{t_{0}^{\text {real }}}
$$

where $T_{c r}^{l u}=0.0729$ and $T_{c r}^{r e a l}=647.1 \mathrm{~K}$ are determined from P-R equation of state, ${ }^{l u}$ $=7.25$ and $l_{0}^{\text {real }}=1.4 \mathrm{~mm}$ are determined from Eq.(20), ${ }^{t_{0}^{l u}}=155.5$ and ${ }_{0}^{t^{\text {real }}}=12.0 \mathrm{~ms}$ are determined from Eq.(21).

Table. 1 lists values of parameters used for computation of condensation on a downward-facing smooth cooler $\left(H^{*}=H / l_{0}=2.8\right)$ with hydrophilic spots $\left(L_{s}^{*}=L_{s} /\right.$ $\left.l_{0}=0.7\right)$ on the bottom surface $(y=H)$ of the hydrophobic wall. The numerical results are presented in the following sections.

Table. 1. Parameters used for computation of condensation with $H^{*}=H / l_{0}=2.8$ and 


\begin{tabular}{|c|c|c|c|c|c|}
\hline \multicolumn{6}{|c|}{$L_{s}{ }^{*}=L_{s} / l_{0}=0.7$} \\
\hline $\begin{array}{l}\text { Case } \\
\text { No. }\end{array}$ & $L_{c}^{*}=L_{c} / l_{0}$ & $d^{*}=d / l_{0}$ & $\theta_{\mathrm{s}}$ & $\theta_{\mathrm{w}}$ & $\begin{array}{c}\text { Number of } \\
\text { hydrophilic spots }\end{array}$ \\
\hline 1 & 11.7 & 5.2 & $33.1^{\mathrm{o}}-88.2^{\mathrm{o}}$ & $104.7^{\circ}-165.3^{\circ}$ & 1 \\
\hline 2 & 36.6 & 5.2 & $55.1^{\circ}$ & $137.8^{\circ}$ & \multirow{6}{*}{5} \\
\hline \multirow{3}{*}{3} & 28.3 & 4.1 & \multirow{3}{*}{$55.1^{\circ}$} & \multirow{3}{*}{$137.8^{\circ}$} & \\
\hline & 36.6 & 5.2 & & & \\
\hline & 44.8 & 6.9 & & & \\
\hline \multirow{2}{*}{4} & \multirow{2}{*}{44.8} & \multirow{2}{*}{6.9} & \multirow{2}{*}{$55.1^{\circ}$} & $115.7^{\circ}$ & \\
\hline & & & & $137.8^{\circ}$ & \\
\hline 5 & 111.0 & 5.2 & $55.1^{\circ}$ & $137.8^{\circ}$ & 17 \\
\hline
\end{tabular}

\subsection{Dropwise condensation on a hydrophobic surface with a single hydrophilic spot}

In this Section, we focus our attention on simulation results for the dynamic behavior of a single droplet formed on a hydrophilic spot of a hydrophobic wall. Fig.2 shows the schematic of a hydrophobic cooler surface facing downward with a single hydrophilic spot located at its center (Case \#1). Note that the small cooler size $\left(L_{c}^{*}=11.7\right)$ in this case ensure the generation of a single droplet for the study of droplets departure diameter and average cycle time of departure.

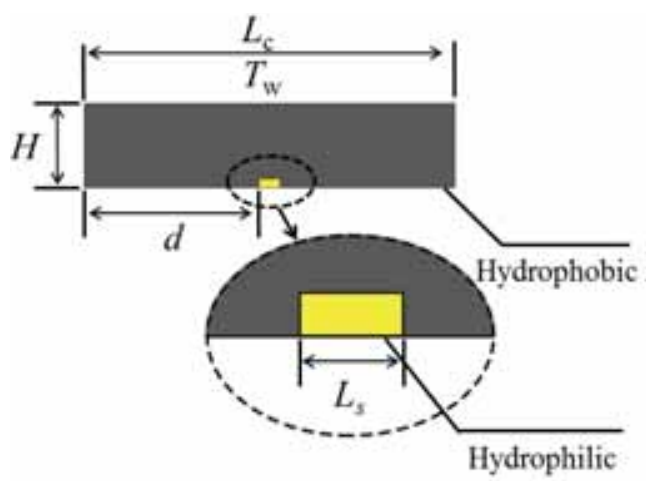

Fig.2. Schematic of location of a single hydrophilic spot on a downward-facing hydrophobic subcooled surface

Fig.3 shows the dynamic behavior of a single droplet formed on a hydrophilic cold spot of a downward facing horizontal hydrophobic surface (Case \#1 with $\left.\theta_{\mathrm{s}}=55.1^{\circ}, \theta_{\mathrm{w}}=137.8^{\circ}\right)$ at a small wall subcooling $(\mathrm{Ja}=0.097)$. The liquid, vapor, wall, spot and thermal insulation material are indicated by red, green, gray, yellow and blue colors respectively. As reported by Liu and Cheng [13], both critical radius and the energy barrier for droplet nucleation increase with increasing contact angle. Fig.3(a) shows that the liquid nucleus is initially formed on the hydrophilic spot. The time at which the first droplet nucleus appears is called nucleation time $\left(t_{\mathrm{n}} *=t_{\mathrm{n}} / t_{0}=113.1\right)$. As 
the condensate droplet grows larger at $t^{*}=199.3$ (Fig. 3(d)), it begins to form a liquid neck because gravity and surface tension effects. At $t^{*}=201.8$, the neck breaks and then a droplet falls from subcooled surface (see Fig. 3(e)) where it can be seen that there is always a residual droplet left on the hydrophilic spot, serving as a nucleus for droplet formation in the next cycle.

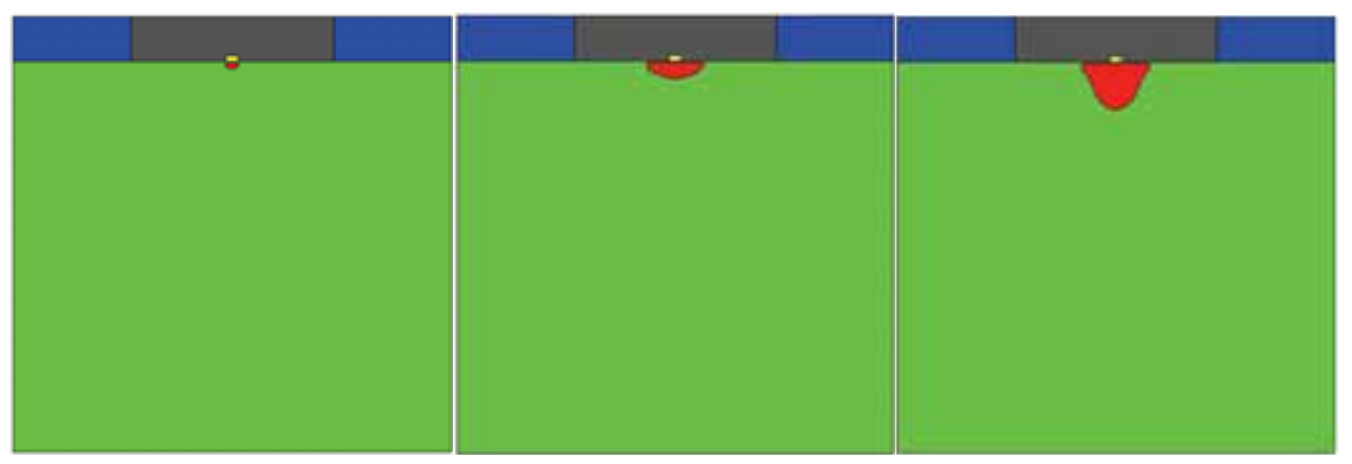

(a) $t^{*}=113.1$

(b) $t^{*}=135.0$

(c) $t^{*}=186.4$

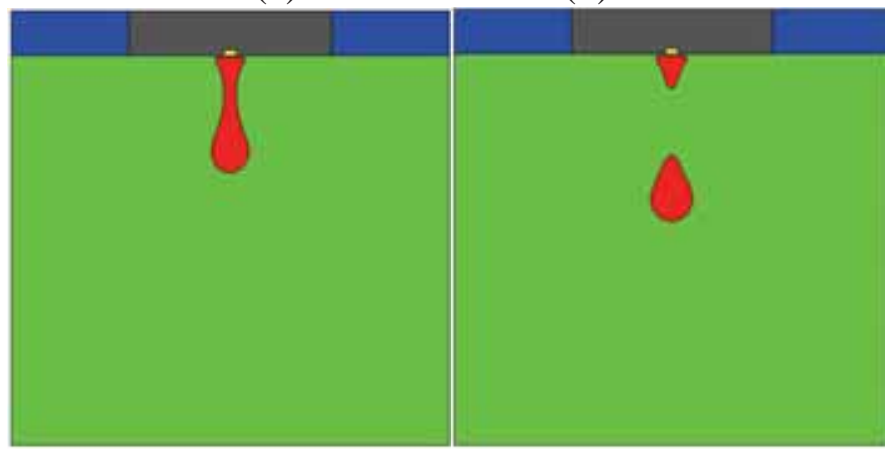

(d) $t^{*}=199.3$

(e) $t^{*}=201.8$

(f) $t^{*}=205.7$

Fig.3. Droplets growth and departure on and from the hydrophilic subcooled spot of a downward-facing hydrophobic subcooled surface (Case \#1 with $\theta_{\mathrm{s}}=55.1^{\circ}$, $\left.\theta_{\mathrm{w}}=137.8^{\circ}\right)$ at $J a=0.097$ under constant wall temperature conditions.

Figs.4(a),4(b) and 4(c) shows transient velocity distributions around droplet corresponding to Figs. 3(b), 3(d) and 3(e). Fig.4(a) shows that the saturated vapor flows upward towards the liquid-vapor interface and condenses into the growing droplet at $t^{*}=135.0$. It is noted that two symmetric counter-rotating circulations begin to form around triple-phase contact line regions (indicated by white dashed rectangles). Fig.4(b) shows that a neck is formed because of gravity and surface tension effects at $t^{*}=199.3$. Due to the viscous effect, the surrounding vapor is dragged by the moving droplet to flow downward and two symmetric counter-rotating circulations near the droplet are formed and move with the falling droplet. Fig.4(c) shows that the residual droplet retracts and spreads to circumference after breaking of the neck at $t^{*}=201.8$. 


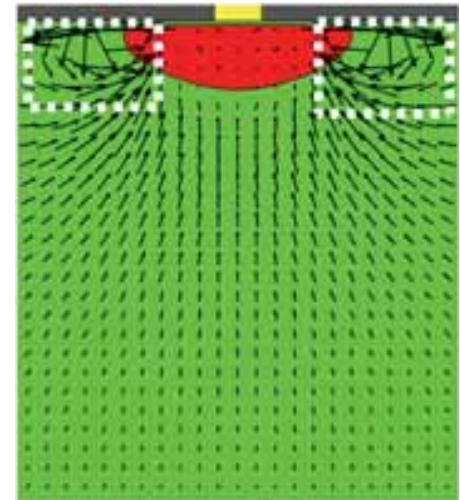

(a) $t^{*}=135.0$

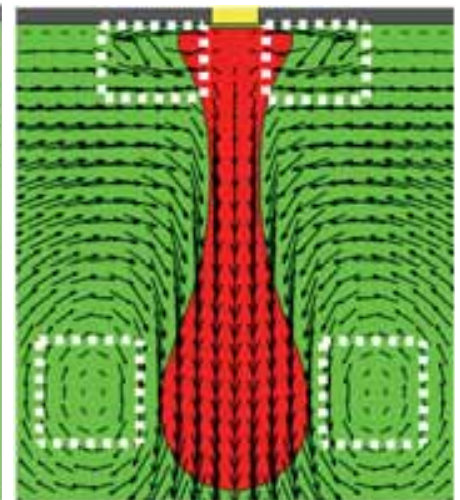

(b) $t^{*}=199.3$

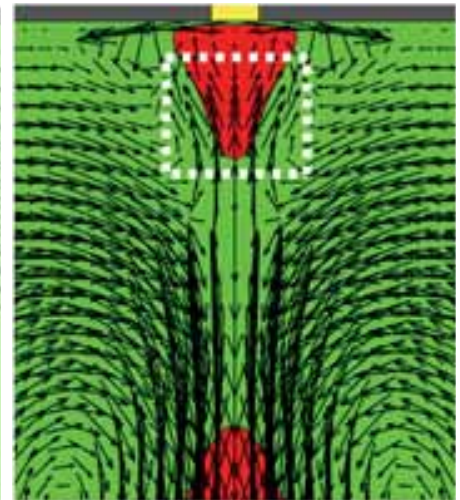

(c) $t^{*}=201.8$

Fig.4. Velocity field inside and outside of the droplet departing from the hydrophilic spot on a downward-facing hydrophobic subcooled surface under constant wall temperature conditions (Case \#1 with $\theta_{\mathrm{s}}=55.1^{\circ}, \theta_{\mathrm{w}}=137.8^{\circ}$ ) at $J a=0.097$.

Fig.5 shows effects of wall subcooling $(\mathrm{Ja})$ and wall wettability $\left(\theta_{\mathrm{w}}=115.7^{\circ}\right.$ and $137.8^{\circ}$ ) on the dimensionless departure diameter $D^{*}$ (defined as $D^{*}=D / l_{0}$ ) of the first droplet and the dimensionless average cycle time $t_{c} *$ (defined as $t_{c}{ }^{*}=t_{c} / t_{0}$ ) of droplet departure versus $J a$ for Case \#1 with $\theta_{\mathrm{s}}=55.1^{\circ}$. As seen from this figure, the departure diameter of the first droplet increases and the average cycle time decreases with increasing degree of wall subcooling. Beneath the cooler surface, the bigger is the droplet, the faster it will fall down from the cooler surface while the smaller one tends to hang on the cooler surface [35]. The residual droplet with larger diameter is more unstable, which contributes to the decrease of the average cycle time. At a sufficiently large wall subcooling, the average cycle time will approach a constant value, which is affected by the contact angle of the wall.

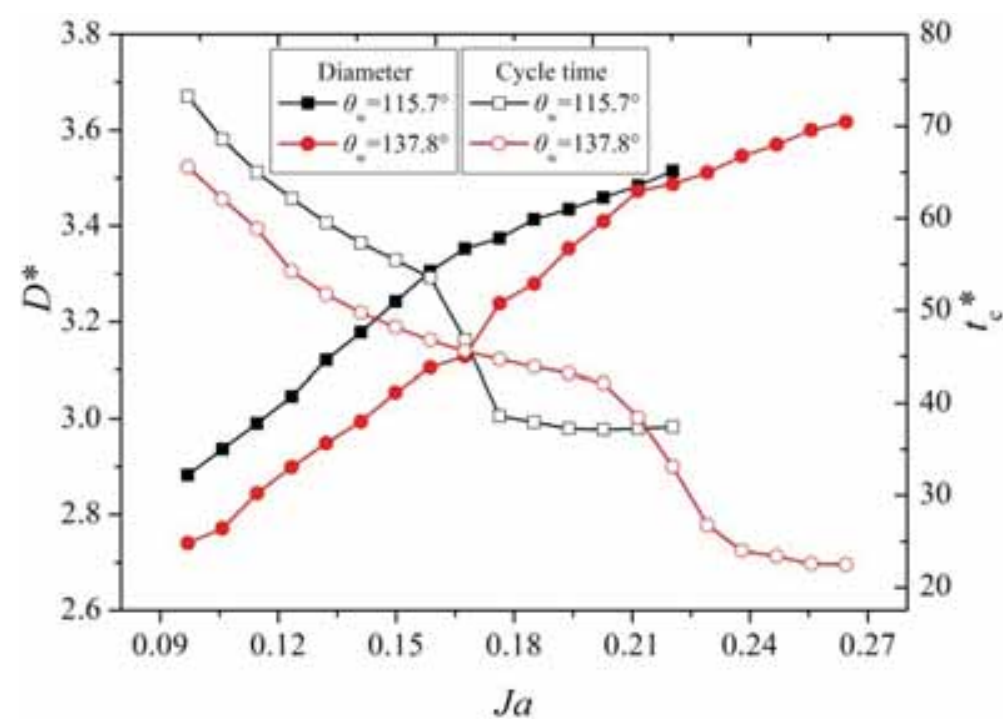

Fig.5. Effects of wall subcooling $(\mathrm{Ja})$ on dimensionless departure diameter of first droplet and dimensionless average cycle time for dropwise condensation on a downward-facing hydrophobic subcooled surface under constant wall temperature conditions (Case \#1 with $\theta_{\mathrm{s}}=55.1^{\circ}$ ). 
As shown from Fig. 3, the size of the hydrophilic spot is small and the larger portion of the droplet is in touch with the hydrophobic wall. Fig. 6 shows that effects of wall wettability $\theta_{\mathrm{w}}$ on dimensionless departure diameter $D^{*}$ of first droplet and the dimensionless average cycle time $t_{\mathrm{c}} *$ (defined as $t_{\mathrm{c}} *=t_{\mathrm{c}} / t_{0}$ ) of droplet departure (Case \#1 with $\theta_{\mathrm{s}}=55.1^{\circ}$ and $71.7^{\circ}, \mathrm{Ja}=0.132$ ). As shown, both departure diameter and average cycle time decrease with increasing $\theta_{\mathrm{w}}$. Since adhesion force to a droplet is weaker on the surface with larger contact angle, the droplet on these surfaces will fall down more frequently with a smaller diameter under gravity effects. Moreover, since the hydrophilic spot is small and it is total covered by the droplet, so that the effect of spot's wettability $\theta_{\mathrm{s}}$ on departure diameter and average cycle time are almost negligible.

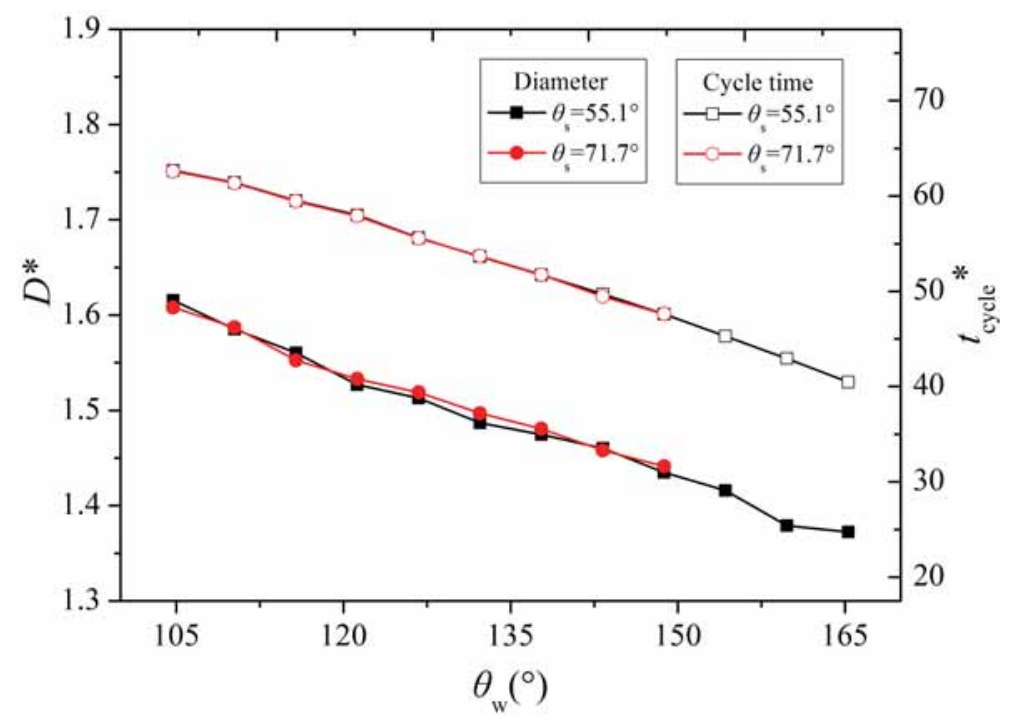

Fig.6. Effects of wall's wettability on dimensionless departure diameter of first droplet and average cycle time for dropwise condensation on a downwardfacing hydrophobic subcooled surface under constant wall temperature conditions (Case \#1 at $J a=0.132$ ).

Fig.7 shows effects of spot's wettability $\theta_{s}$ and wall's wettability $\theta_{w}$ on dimensionless droplet nucleation time $t_{\mathrm{n}} *$ (defined as $t_{\mathrm{n}}{ }^{*}=t_{\mathrm{n}} / t_{0}$ ) (Case \#1 with $\theta_{\mathrm{w}}=115.7^{\circ}$ and $\left.137.8^{\circ}\right)$ at $J a=0.132$ and 0.176 before the appearance of first nucleated droplet. Before droplet nucleation, the cold spot is exposed to saturated steam. The wettability of cold spot has a large effect on droplet nucleation time. According to the classical nucleation theory, the nucleation rate on a surface with contact angle $\theta$ can be calculated by [36]

$$
J=J_{0} \exp \left[-\frac{\pi \sigma_{l v} r_{c}^{2}\left(2-3 \cos \theta+\cos ^{3} \theta\right)}{3 k T_{\mathrm{w}}}\right]
$$

where $J_{0}$ is a kinetic constant, $\sigma_{l v}$ is surface tension, $r_{\mathrm{c}}$ is critical radius, $k$ is Boltzmann constant, $T_{\mathrm{w}}$ is the temperature of cooler surface. The nucleation time is inversely proportional to the nucleation rate [36], i.e.,

$$
\left.t_{\mathrm{n}}^{*}\right]_{J}^{1}
$$


With increasing contact angle of both wall and spot, it follows from Eq.(24a) that the nucleation rate decreases while the droplet nucleation time increases according to Eq. (24b). In addition, the larger wall subcooling will result in a shorter droplet nucleation time. These behaviors are confirmed by simulation results shown in Fig.7.

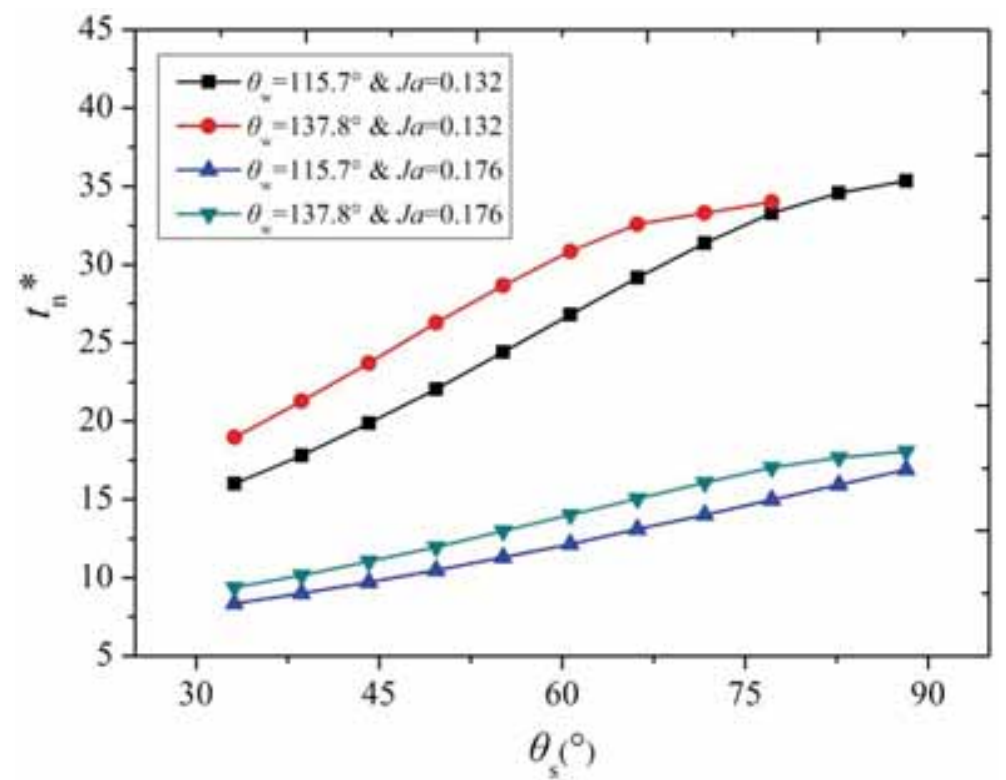

Fig.7. Effects of spot's wettability and wall's wettability on dimensionless nucleation time under constant wall temperature conditions (Case \#1).

3.3 Transition from dropwise to filmwise condensation on a downward-facing horizontal hydrophobic surface with multiple hydrophilic spots

In this section, we focus our attention on the transition from dropwise to filmwise condensation on a downward-facing hydrophobic subcooled surface having multiple hydrophilic spots with a pitch distance $d$. Computations were carried out for a hydrophobic subcooled surface with 5 hydrophilic spots as shown in Fig.8, where the cooler has a length of $L_{c}$ and a thickness of $H$. The size of hydrophilic spots is constant with a uniform pitch distance $d$.

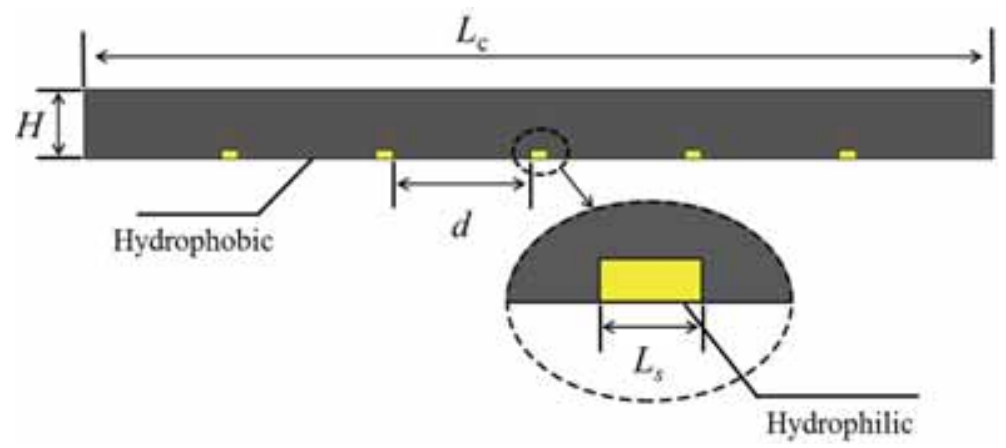

Fig.8. Schematic of locations of a downward-facing hydrophobic subcooled surface with five hydrophilic spots .

\subsubsection{Droplets growth, coalescence and departure under constant wall temperature}


Fig.9 presents the droplets growth, coalescence and departure on a downwardfacing horizontal hydrophobic surface with $L_{c}{ }^{*}=36.6$ having 5 hydrophilic spots (Case \#2) at a low wall subcooling of $J a=0.150$. Fig.9(a) shows that five droplets are growing below the 5 hydrophilic spots at $t^{*}=128.6$. Fig.9(b) shows tiny liquid bridges between two adjacent droplets near the ends are formed at $t^{*}=135.0$. Fig.9(c) shows that two droplets near the two ends coalesce to form two larger droplets at $t^{*}=147.8$. Fig.9(d) shows that these two large droplets fall down from the subcooled surface at $t^{*}=158.1$ because of gravity while the smaller droplet on the center hangs on the wall.

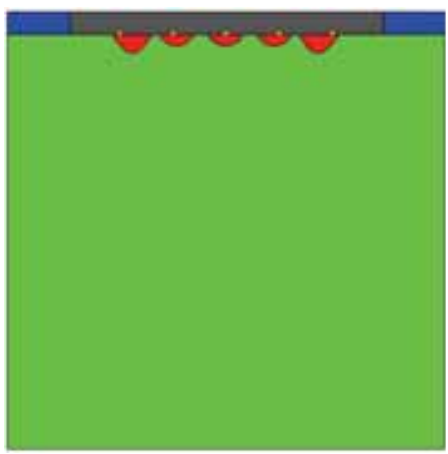

(a) $t^{*}=128.6$

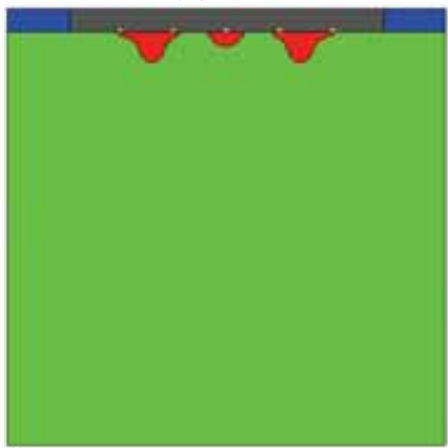

(c) $t^{*}=147.8$

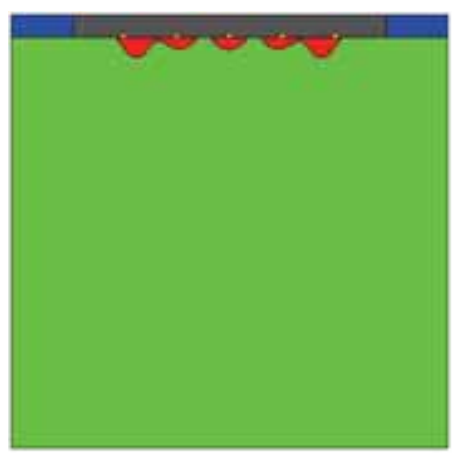

(b) $t^{*}=135.0$

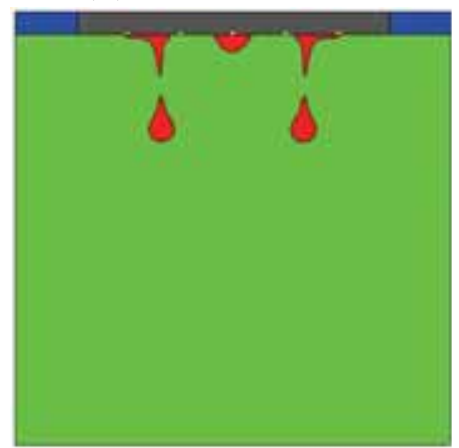

(d) $t^{*}=158.1$

Fig.9. Droplets coalescence and departure during dropwise condensation on a downward-facing horizontal hydrophobic subcooled surface $\left(L_{c} *=36.6\right)$ with 5 hydrophilic spots $\left(d^{*}=5.2\right)$ under constant wall temperature conditions (Case \#2) at a low wall subcooling of $J a=0.150$.

With further increase in wall subcooling, transition from dropwise condensation to filmwise condensation will take place. Fig.10 presents the behavior of the condensate liquid film during filmwise condensation on a horizontal downwardfacing hydrophobic surface with $L_{c}{ }^{*}=36.6$ having 5 hydrophilic spots (Case \#2) at a large wall subcooling of $J a=0.194$. Fig.10(a) shows that five droplets are formed below the five hydrophilic spots at $t^{*}=45.0$ at this wall subcooling. Fig.10(b) shows that tiny liquid bridges between adjacent droplets are formed and the droplets coalesce into liquid film rapidly at $t^{*}=55.3$. After filmwise condensation occurs, the 5 hydrophilic spots have no effect on condensation heat transfer. Owing to gravity and surface tension effects, the liquid film is unstable because of Taylor instability [35]. As a result, the thickness of liquid film will fluctuate spatially with time and form two falling droplets near the two ends as shown in Fig.10(c). The droplets fall down from 
the downward-facing surface at $t^{*}=91.3$ (Fig.10(d)). The liquid of broken neck will retract and spread to the circumference. The growth, departure of droplets and retraction of liquid film on the subcooled surface occur cyclically.

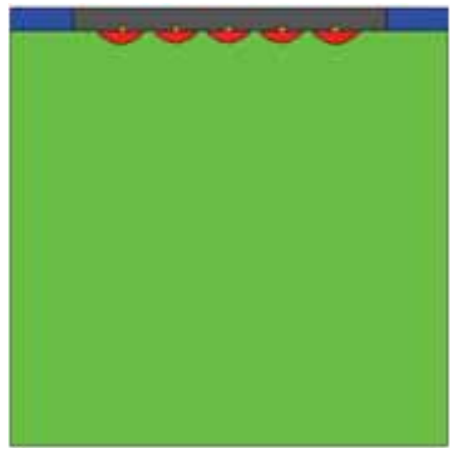

(a) $t^{*}=45.0$

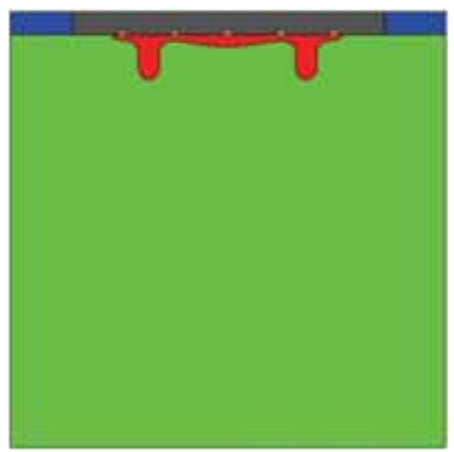

(c) $t^{*}=83.6$

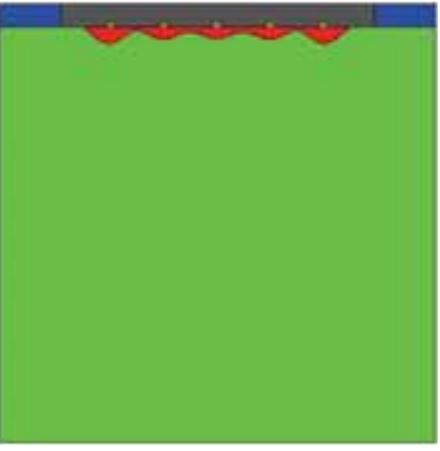

(b) $t^{*}=55.3$

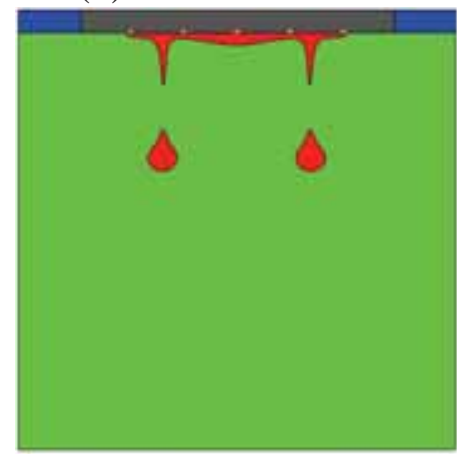

(d) $t^{*}=91.3$

Fig.10. Droplets coalescence and formation of a liquid film on a downward-facing horizontal hydrophobic surface with 5 hydrophilic spots $\left(d^{*}=5.2\right)$ under constant wall temperature conditions (Case \#2) at a high wall subcooling of $\mathrm{Ja}$ $=0.194$.

After departure of droplets from the subcooled surface, some areas are newly exposed to the vapor. The rate of condensation on these areas increases with the increase of wall subcooling. Under sufficiently large wall subcoolings, the area is covered quickly by newly formed condensate. As a result, the mode of condensation will change from dropwise condensation into filmwise condensation. These simulation results agree with the second possible transition mechanism proposed by Rose [4, 7] who suggested that transition from dropwise condensation to filmwise condensation occurred at a sufficiently high condensation heat flux when the rate at which new surface was exposed by droplet coalescences was smaller than the rate of droplet formation on the surface.

\subsubsection{Temperature distribution and local heat flux}

The dimensionless local heat flux on the cooler surface at $y=H$ can be calculated as: 


$$
q *(x, H, t)=\frac{\left(-\lambda \frac{\partial T}{\partial y}\right)_{y=H}}{q_{0}}=\frac{1}{\mu_{l} h_{f g}} \sqrt{\frac{\sigma}{g\left(\rho_{l}-\rho_{v}\right)}}\left(-\lambda \frac{\partial T}{\partial y}\right)_{y=H}
$$

where $q_{0}=\mu_{l} h_{f g} \sqrt{g\left(\rho_{\text {可 }}-\rho_{v}\right) / \sigma}$ is the reference condensation heat flux, $q_{0}^{l u}=0.027$, $q_{0}^{\text {real }}=78.463 \mathrm{~kW} / \mathrm{m}^{2}{ }_{\text {[37] }} \lambda$ is the thermal conductivity of the cooler, $\mu_{l}$ is the dynamic viscosity of the liquid.

Fig.11(a) shows the dimensionless temperature field of dropwise condensation on a hydrophobic surface with 5 hydrophilic spots at a small degree of subcooling under constant wall temperature conditions (Case \#2) at $J a=0.097$ and $t^{*}=128.6$. The white curves indicate the shape of the droplets. Fig.11(b) presents the corresponding local heat flux distribution on the subcooled surface where the droplets are growing at this moment before falling down. Due to the effect of latent heat released during condensation, the temperature around liquid-vapor interface is much higher than elsewhere, especially near the triple-phase contact line region. Isotherms in the computation domain are distorted, which results from the physical property of different phases and the non-uniform local heat flux distribution caused by dropwise condensation. As we can see, isotherms are more crowded and local heat flux is much higher on the subcooled surface underneath the droplets than other areas where no phase change takes place. In particular, isotherms are most dense in the triple-phase contact line region where the local heat flux is highest, which is verified in Fig.11(b).

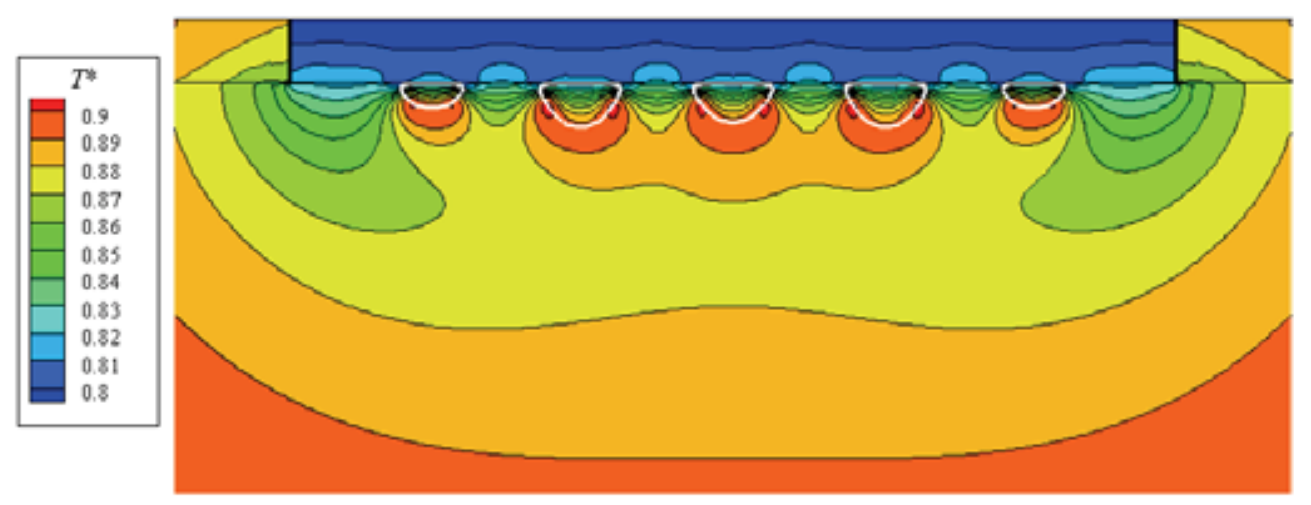

(a) Temperature field during dropwise condensation

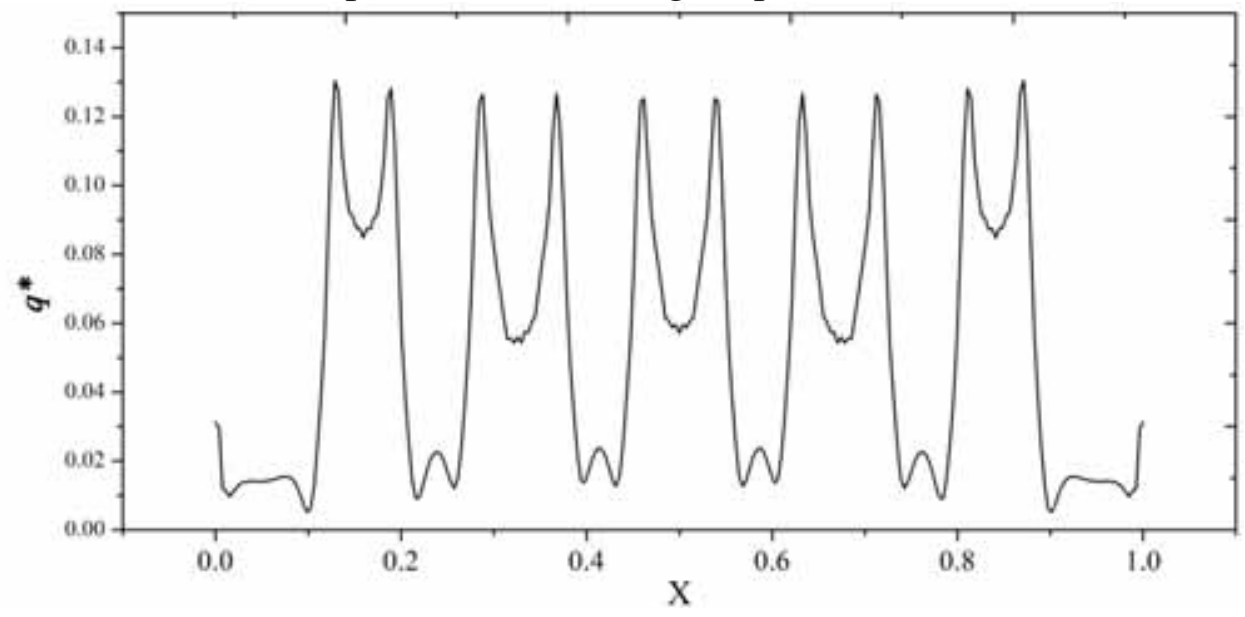

(b) Local heat flux distribution on the subcooled surface 
Fig.11. (a) Temperature and (b) local heat flux distributions during dropwise condensation on a downward-facing hydrophobic subcooled surface (Case \#2) at small wall subcoolings $(\mathrm{Ja}=0.097)$ under constant wall temperature conditions at $t^{*}=128.6$.

Fig.12(a) shows the temperature field of filmwise condensation and Fig.12(b) shows the corresponding local heat flux distribution on a hydrophobic surface with 5 hydrophilic spots at a larger subcooling under constant wall temperature conditions (Case \#2 with $J a=0.194, t^{*}=109.3$ ). The shape of the liquid film is indicated by white curve. Similar to the previous discussion about dropwise condensation in the previous paragraphs, the temperature around liquid-vapor interface is much higher and the local heat flux on the surface covered with liquid film is higher than the region without phase change. Also, the local heat flux is higher where the liquid film is thinner, which was reported in the experiments conducted by Yanadori [38]. In the triple-phase contact line region, the condensation rate is the highest and the liquid film is thin, which result in higher local heat flux and more crowed isotherms in these areas.
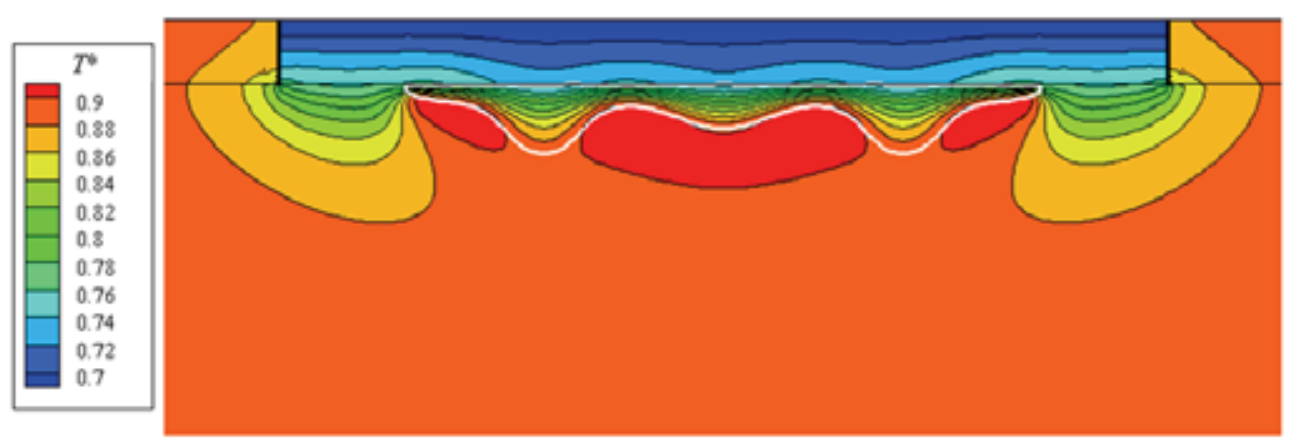

(a) Temperature field during filmwise condensation

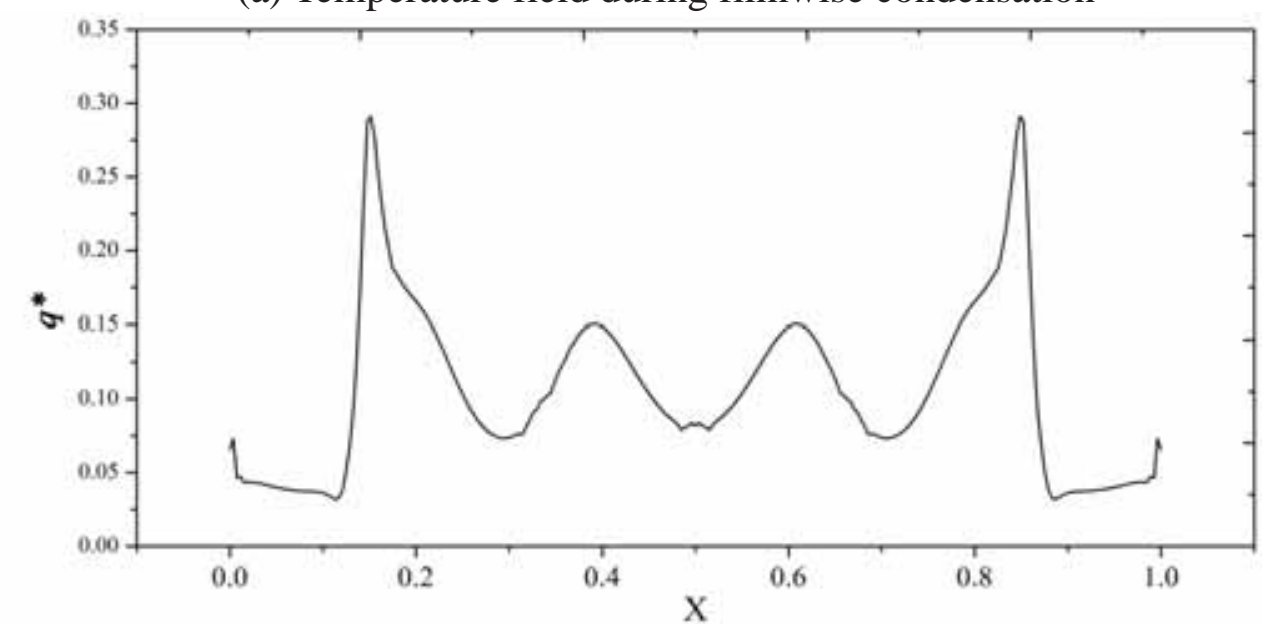

(b) Local heat flux distribution on the subcooled surface

Fig.12. (a) Temperature field and (b) local heat flux distribution during filmwise condensation on a downward facing subcooled surface (Case \#2) at a larger subcooling $(\mathrm{Ja}=0.194)$ under constant wall temperature conditions at $t^{*}=109.3$. 


\subsubsection{Dropwise condensation curves}

The dimensionless space- and time-averaged condensation heat flux is defined as:

$$
q_{\mathrm{ave}}^{*}=\frac{1}{L_{c}\left(t_{b}-t_{a}\right)} \int_{t_{a}}^{t_{b}} \int_{L_{x} / 2-L_{c} / 2}^{L_{x} / 2+L_{c} / 2} q^{*}(x, 0, t) \mathrm{d} x \mathrm{~d} t
$$

where $q(x, 0, t)$ is given by Eq.(25), $L_{x}$ is the length of computational domain in $\mathrm{x}$ direction and $L_{c}$ is the length of cooler $\left(L_{c}=6 d+5 L_{s}\right), t_{a}$ to $t_{b}$ is a long time interval during condensation process.

Fig.13 shows effects of pitch distances $\left(d^{*}=4.1,5.5,6.9\right)$ on dropwise condensation curves (i.e., the averaged heat flux versus $J a$ ) for a downward-facing horizontal hydrophobic surface having 5 hydrophilic spots (Case \#3) under constant wall temperature conditions with different lengths $\left(L^{*}{ }_{c}=4.1,5.2,6.9\right)$. Each dropwise condensation curve can be divided into three regimes: (i) natural convection regime A-B, (ii) dropwise condensation regime B-C, (iii) condensation transition regime C$\mathrm{D}$, and (iv) filmwise condensation regime D-E. When the wall subcooling is small, the heat transfer is carried out by heat conduction in solid and natural convection on the subcooled surface. In this regime, the average heat flux is low and increases slightly with the increase of $J a$. The dropwise condensation starts at point $\mathrm{B}$, and then the average heat flux increases with increasing $J a$ only up to point $\mathrm{C}$. As shown in the small insert $\mathrm{C}$, at point $\mathrm{C}$ with peak heat flux, the dropwise condensation is extremely intense, and the droplets near the center coalesce to form a local liquid film. When the wall subcooling is increased further, the dropwise condensation will transform into filmwise condensation. A complete liquid film forms rapidly (see insert D) and hinders the direct contact between subcooled surface and saturated vapor. As a result, the average heat flux is reduced gradually with the increase of $J a$ during the transition from dropwise to filmwise condensation. In filmwise condensation regime D-E under larger subcooling, the average heat flux increases with the increase of $\mathrm{Ja}$ caused mainly by the increased conduction transport, which is affected by the increasing driving temperature difference across the liquid film. The shape of simulated dropwise condensation curves shown in Fig. 13 are similar to those obtained from experiments [8-10].

The length of pitch distance between hydrophilic spots has important influence on peak condensation heat flux. Droplet is initially formed on hydrophilic spots. The long pitch distance makes droplet coalesce to form a liquid film more difficult on the subcooled surface. Therefore, a larger wall subcooling is required to change dropwise condensation to filmwise condensation. This is confirmed from Fig.13, where it is shown that the peak heat fluxes at C', C and C" are $q^{*}{ }_{\text {ave }}=0.123$ (at $J a=0.141$ ), 0.165 (at $J a=0.185$ ), and 0.170 (at $J a=0.194$ ) for $d^{*}=4.1,5.2$ and 6.9, respectively. Thus, the corresponding peak heat flux increases with the increasing pitch distance. In addition, as the pitch distance is increased, the proportion of high dropwise condensation heat flux area (see Fig.11(b)) covered by droplets decreases, resulting in a lower average heat flux. 


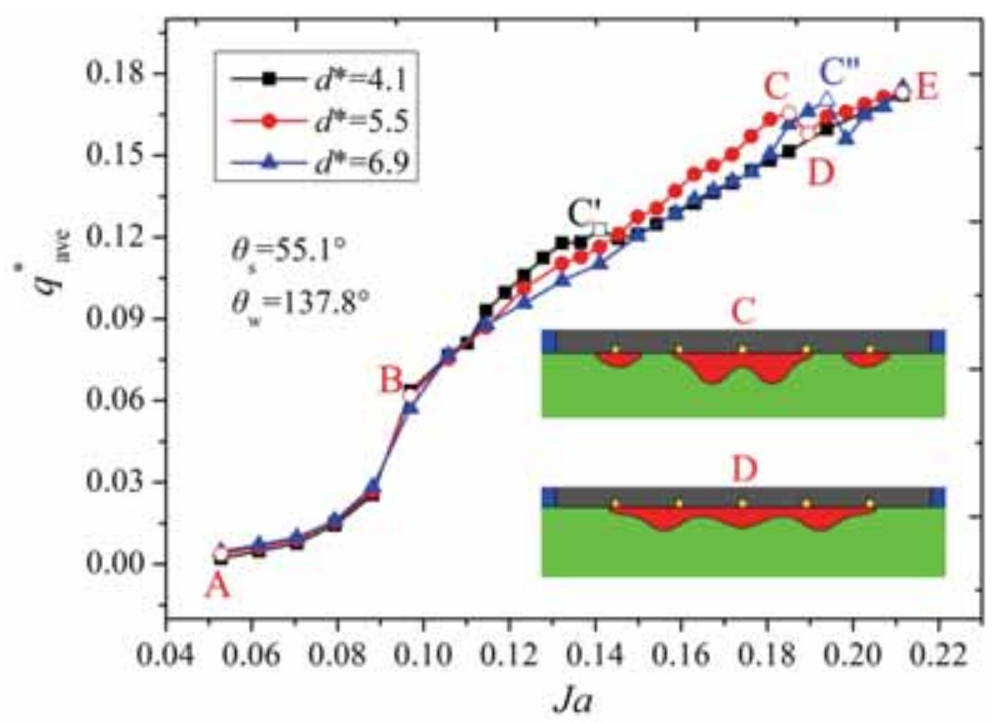

Fig.13. Effects of pitch distances on dropwise condensation curves for downwardfacing hydrophobic subcooled surfaces with hydrophilic spots (Case \#3) under constant wall temperature conditions $(\mathrm{Ja})$.

Fig.14 shows effects of wall's wettability on the dropwise condensation curve for condensation on a downward-facing hydrophobic surfaces with 5 hydrophilic spots with $L^{*}{ }_{c}=44.8$ and $d^{*}=5.2$ (Case \#4). Before the onset of dropwise condensation, the average convective heat fluxes depends on wall's wettability. With the decrease of wall temperature, the dropwise condensation is observed firstly on the cooler with smaller wall contact angle $\left(\theta_{\mathrm{w}}=115.7^{\circ}\right)$. As shown in the small inserts, the droplets on the surface with smaller $\theta_{\mathrm{w}}$ (insert $\mathrm{F}$ ) have a smaller height in vertical direction and more area in contact of the droplet than those with larger $\theta_{\mathrm{w}}$ (insert $\mathrm{G}$ ), which results in the decreasing thermal resistance of conduction across the droplet and the increasing proportion of high heat flux area covered by droplets (see Fig.11(b)). That is the reason why the average heat flux on the subcooled surface with smaller $\theta_{\mathrm{w}}$ is higher in dropwise condensation regime. When the wall subcooling is increased further, dropwise condensations will change into filmwise condensation depending on the value of the contact angle. The transition from dropwise to filmwise condensation occurs at C" and C" "where the peak dropwise condensation heat flux is reached. It is noted that the subcooled surface with smaller $\theta_{\mathrm{w}}\left(\theta_{\mathrm{w}}=115.7^{\circ}\right)$ has a lower peak heat flux at C" with a small wall subcooling $(J a=0.159)$. In other words, with same distribution of hydrophilic spots, transition from dropwise to filmwise condensation is easier to occur on a surface with a smaller contact angle. 


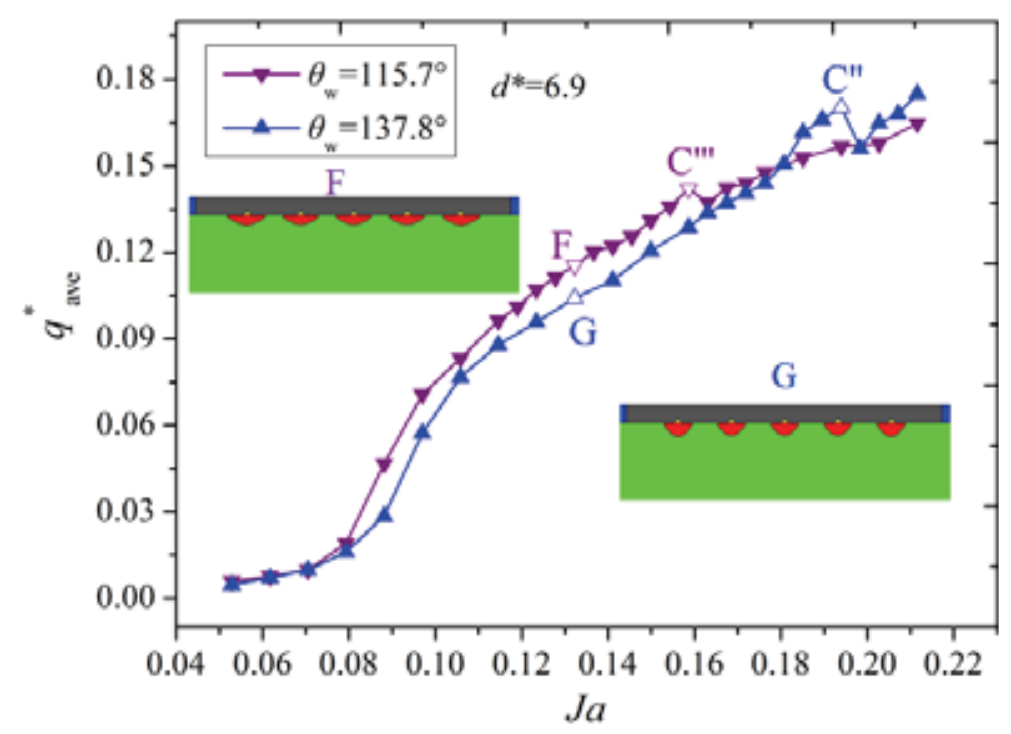

Fig.14. Effects of wall's wettability on dropwise condensation curves for downwardfacing hydrophobic surfaces with 5 hydrophilic spots under constant wall temperature conditions ( $\mathrm{Ja}$ ) (Case \#4).

\subsection{Dropwise condensation curve under constant heat flux}

In this section, we focus our attention on condensation heat transfer under constant heat flux conditions. Fig. 15 shows dropwise condensation curve (represented by square solid symbols) for a hydrophobic surface with 5 hydrophilic spots (Case \#2) under constant heat flux conditions. The small inserted figures show the temperature field around subcooled surface for dropwise condensation $(\mathrm{F})$ at low wall subcooling ( $J a=0.091)$ and filmwise condensation $(\mathrm{G})$ at high wall subcooling $(\mathrm{Ja}=0.196)$. The shapes of droplets and liquid film are indicated by white curves in inserted figures. These temperature fields are similar to those under constant wall temperature conditions shown in Figs.11(a) and 12(a) respectively. The isotherms are distorted and particularly crowded in the triple-phase contact line region. However, under constant heat flux conditions, the temperature of top surface of cooler at $y=0$ is not uniform with the coldest wall temperature at the center.

For comparison purpose, the dropwise condensation curve for $d^{*}=5.5$ under constant wall temperature conditions in Fig.13 is also plotted as a red solid curve in Fig.15. As shown, the dropwise condensation curve under constant heat flux conditions is almost in agreement with those under constant wall temperature conditions everywhere except in transition regime from dropwise condensation to filmwise condensation. During the condensation transition regime, a stable liquid film is formed on the subcooled surface and hinders direct contact between cooler and saturated vapor. As a result, there is a sudden temperature drop of subcooled surface (i.e. a sudden increase of $J a$ ) with a slight increase of heat flux under constant heat flux conditions. On the other hand, the transition from dropwise condensation to filmwise condensation takes place gradually under constant wall temperature conditions, and thus heat flux reduction is observed gradually with an increase of wall subcooling (Fig. 13). This is the most important difference in dropwise condensation curves under these two heating methods. In the filmwise condensation regime, the wall subcooling increases with increasing heat flux in both heating methods. 


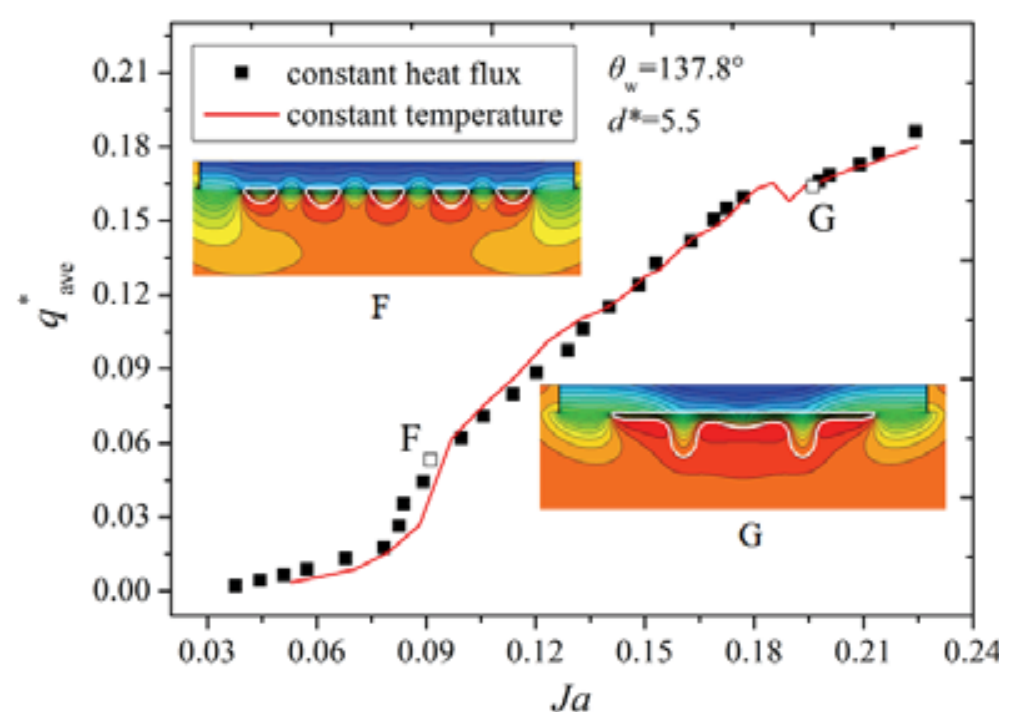

Fig.15. Comparison of dropwise condensation curves on a downward-facing horizontal hydrophobic surface with 5 hydrophilic spots (Case \#2) under constant wall temperature and constant heat flux conditions .

\subsection{Droplets falling patterns during filmwise condensation}

The "most dangerous" Taylor wavelength [39] can be calculated from:

$$
\lambda_{D}=2 \pi \sqrt{\frac{3 \sigma}{\left(\rho_{l}-\rho_{v}\right) g}} \approx 10.88 l_{0}
$$

In this section, we will investigate whether Taylor instability occurs on filmwise condensation on the downward facing horizontal subcooled surface. For this purpose, simulation is carried out for condensation on a large subcooled hydrophobic surface with $L_{c}{ }^{*}=111.0$ (Case \#5) at a large wall subcooling at $J a=0.212$ under constant wall temperature conditions. Simulation results for droplet falling down from 9 locations at 4 different times are presented in Fig.16. The distance between the left-most and right-most droplets is about 628lu $\left(86.62 l_{0}\right)$, and the average distance between two droplets is $86.62 l_{0} / 8=10.83 l_{0}$. This wavelength is in agreement with those calculated based on Taylor's unstable wavelength subcooled by Eq.(27). Thus, simulation results confirm that droplets fall down in filmwise condensation on locations according to the wavelength of Taylor instability.

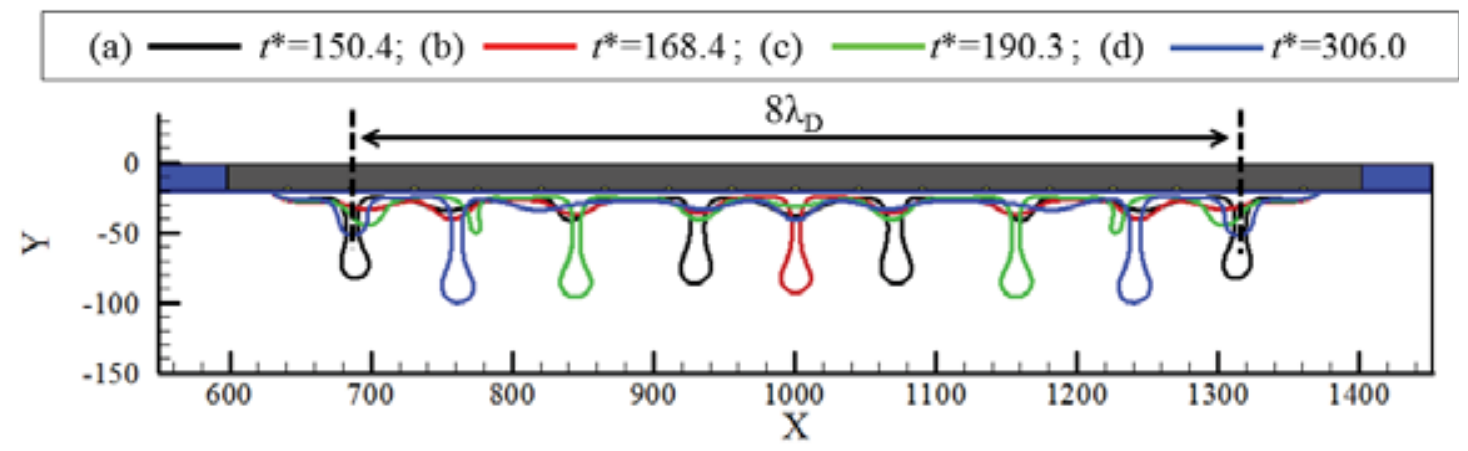

Fig.16. Droplets fall down from the downward facing horizontal subcooled surface under constant wall temperature condition at $\mathrm{Ja}=0.212$ (Case \#5). 


\section{Concluding remarks}

In this paper, condensation on downward-facing smooth horizontal hydrophobic surfaces with hydrophilic spots is numerically simulated based on Gong-Cheng's phase-change lattice Boltzmann model. The growth, coalescence and departure of condensate droplets on the subcooled surface are investigated numerically. Temperature fields as well as local heat fluxes are analyzed. Effects of wall subcooling and wettability, as well as wettability of spots and their pitch distances on condensation heat transfer are presented. The following conclusions can be drawn from this paper:

(i) Dropwise condensation curves in terms of dimensionless averaged condensation heat flux versus dimensionless wall subcooling (i.e., the Jacob number) under various conditions are obtained numerically. It is shown that with increasing wall subcooling, the heat transfer mode on the downwardfacing smooth horizontal mixed wettability surface changes from natural convection, dropwise condensation to filmwise condensation successively.

(ii) The departure diameter of first droplet increases and average cycle time of droplets departure decreases with increase of wall subcooling. They both increase with the increasing wettability of wall. The droplet nucleation time increases with increasing contact angle of hydrophilic spots.

(iii) The location in contact of the droplet has a high local heat flux especially around the triple-phase contact line during dropwise condensation. The local heat flux is higher where the liquid film is thinner during filmwise condensation.

(iv) The peak dropwise condensation heat flux and the corresponding wall subcooling increase with increasing pitch distance between hydrophilic spots or with the increasing static contact angle of the hydrophobic wall.

(v) During transition from dropwise to filmwise condensation, there is a sudden temperature drop on the subcooled surface under constant heat flux conditions while there is a gradual heat flux reduction under constant wall temperature conditions.

(vi) At small wall subcoolings, droplets are formed on the hydrophilic spots. As the wall subcooling is increased, droplets begin to coalesce and filmwise condensation occurs. Subsequently, droplets fall down because of gravity from the cooler surface at locations according to Taylor's unstable wavelength.

\section{Conflict of interest}

None declared.

\section{Acknowledgements}

This work was supported by National Science Foundation of China through Grant Nos. 51420105009 and 51521004.

\section{References}

[1] J. Chung, S. Kandlikar, Boiling and condensation, in: Multiphase Flow Handbook, CRC Press, 2005.

[2] W. Nusselt, Die Oberflachenkondesation des Wasserdamffes the surface condensation of water, 
Zetrschr. Ver. Deutch. Ing., 60 (1916) 541-546.

[3] E. LeFevre, J. Rose, A theory of heat transfer by dropwise condensation, in: Proceedings of 3rd International Heat Transfer Conference, Chicago, 1966, pp. 362-375.

[4] J.W. Rose, On the mechanism of dropwise condensation, International Journal of Heat and Mass Transfer, 10(6) (1967) 755-762.

[5] T. Takeyama, S. Shimizu, On the transition of dropwise-film condensation, Heat Transfer, 3 (1974) 274-278.

[6] I. Tanasawa, Y. Utaka, Measurement of Condensation Curves for Dropwise Condensation of Steam at Atmospheric Pressure, Journal of Heat Transfer, 105(3) (1983) 633-638.

[7] S.A. Stylianou, J.W. Rose, Drop-to-filmwise condensation transition: Heat transfer measurements for ethanediol, International Journal of Heat and Mass Transfer, 26(5) (1983) 747-760.

[8] Y. Utaka, A. Saito, T. Tani, H. Shibuya, K. Katayama, Study on Dropwise Condensation Curves : Measurement of Propylene Glycol Vapor on PTFE Coated Surface, Bulletin of JSME, 28(240) (1985) 1150-1157.

[9] Y. Utaka, A. Saito, H. Ishikawa, H. Yanagida, Study on Dropwise Condensation Curves : Dropwise to Filmwise Transition of Propylene Glycol, Ethylene Glycol and Glycerol Vapors on a Copper Surface Using a Monolayer Type Promoter (Part 1), Bulletin of JSME, 29(258) (1986) 4228-4234.

[10] Y. Utaka, A. Saito, H. Ishikawa, H. Yanagida, Study on dropwise condensation curves (dropwise to filmwise transition of propylene glycol, ethylene glycol and glycerol vapors on a copper surface using a monolayer type promoter - part 2), JSME International Journal, Series B: Fluids and Thermal Engineering, 31(1) (1988) 73-80.

[11] X. Ma, Z. Lan, W. Xu, M. Wang, S. Wang, Effect of surface free energy difference on steamethanol mixture condensation heat transfer, International Journal of Heat and Mass Transfer, 55(4) (2012) 531-537.

[12] H.J. Cho, D.J. Preston, Y. Zhu, E.N. Wang, Nanoengineered materials for liquid-vapour phase-change heat transfer, Nature Reviews Materials, 2 (2016) 16092.

[13] X. Liu, P. Cheng, Dropwise condensation theory revisited: Part I. Droplet nucleation radius, International Journal of Heat and Mass Transfer, 83 (2015) 833-841.

[14] X. Liu, P. Cheng, Dropwise condensation theory revisited Part II. Droplet nucleation density and condensation heat flux, International Journal of Heat and Mass Transfer, 83 (2015) 842-849.

[15] A. Chatterjee, M.M. Derby, Y. Peles, M.K. Jensen, Enhancement of condensation heat transfer with patterned surfaces, International Journal of Heat and Mass Transfer, 71 (2014) 675-681.

[16] A. Ghosh, S. Beaini, B.J. Zhang, R. Ganguly, C.M. Megaridis, Enhancing Dropwise Condensation through Bioinspired Wettability Patterning, Langmuir, 30(43) (2014) 13103-13115.

[17] P.S. Mahapatra, A. Ghosh, R. Ganguly, C.M. Megaridis, Key design and operating parameters for enhancing dropwise condensation through wettability patterning, International Journal of Heat and Mass Transfer, 92 (2016) 877-883.

[18] B. Peng, X. Ma, Z. Lan, W. Xu, R. Wen, Experimental investigation on steam condensation heat transfer enhancement with vertically patterned hydrophobic-hydrophilic hybrid surfaces, International Journal of Heat and Mass Transfer, 83 (2015) 27-38.

[19] B. Peng, X. Ma, Z. Lan, W. Xu, R. Wen, Analysis of condensation heat transfer enhancement with dropwise-filmwise hybrid surface: Droplet sizes effect, International Journal of Heat and Mass Transfer, 77 (2014) 785-794.

[20] Y.-A. Lee, L.-S. Kuo, T.-W. Su, C.-C. Hsu, P.-H. Chen, Orientation effects of nanoparticlemodified surfaces with interlaced wettability on condensation heat transfer, Applied Thermal Engineering, 98 (2016) 1054-1060.

[21] C. Aghanajafi, K. Hesampour, Heat Transfer Analysis of a Condensate Flow by VOF Method, Journal of Fusion Energy, 25(3) (2006) 219.

[22] E. Da Riva, D. Del Col, Numerical Simulation of Laminar Liquid Film Condensation in a Horizontal Circular Minichannel, Journal of Heat Transfer, 134(5) (2012) 051019-051019.

[23] Z. Liu, B. Sunden, J. Yuan, VOF modeling and analysis of filmwise condensation between vertical parallel plates, 43(1) (2012) 47-68.

[24] S. Gong, P. Cheng, A lattice Boltzmann method for simulation of liquid-vapor phase-change heat transfer, International Journal of Heat and Mass Transfer, 55(17-18) (2012) 4923-4927.

[25] S. Gong, P. Cheng, Lattice Boltzmann simulation of periodic bubble nucleation, growth and departure from a heated surface in pool boiling, International Journal of Heat and Mass Transfer, 64 (2013) 122-132.

[26] S. Gong, P. Cheng, Lattice Boltzmann simulations for surface wettability effects in saturated 
pool boiling heat transfer, International Journal of Heat and Mass Transfer, 85 (2015) 635-646.

[27] X. Liu, P. Cheng, Lattice Boltzmann simulation of steady laminar film condensation on a vertical hydrophilic subcooled flat plate, International Journal of Heat and Mass Transfer, 62 (2013) 507-514.

[28] X. Liu, P. Cheng, Lattice Boltzmann simulation for dropwise condensation of vapor along vertical hydrophobic flat plates, International Journal of Heat and Mass Transfer, 64 (2013) 1041-1052.

[29] S. Gong, P. Cheng, Numerical investigation of droplet motion and coalescence by an improved lattice Boltzmann model for phase transitions and multiphase flows, Computers \& Fluids, 53 (2012) 93-104.

[30] X. Shan, H. Chen, Lattice Boltzmann model for simulating flows with multiple phases and components, Physical Review E, 47(3) (1993) 1815-1819.

[31] A.L. Kupershtokh, D.I. Karpov, D.A. Medvedev, C.P. Stamatelatos, V.P. Charalambakos, E.C. Pyrgioti, D.P. Agoris, Stochastic models of partial discharge activity in solid and liquid dielectrics, IET Science, Measurement \& Technology, 1(6) (2007) 303-311.

[32] Z. Guo, C. Zheng, B. Shi, Discrete lattice effects on the forcing term in the lattice Boltzmann method, Physical Review E, 65(4) (2002) 046308.

[33] S. Chen, D. Martínez, R. Mei, On boundary conditions in lattice Boltzmann methods, Physics of Fluids, 8(9) (1996) 2527-2536.

[34] G. Son, V.K. Dhir, N. Ramanujapu, Dynamics and Heat Transfer Associated With a Single Bubble During Nucleate Boiling on a Horizontal Surface, Journal of Heat Transfer, 121(3) (1999) 623-631.

[35] R. Bellman, R.H. Pennington, Effects of surface tension and viscosity on Taylor instability, Quarterly of Applied Mathematics, 12(2) (1954) 151-162.

[36] K. Ken, L.G. Alan, Nucleation in condensed matter: applications in materials and biology, Elsevier, 2010.

[37] S. Gong, P. Cheng, X. Quan, Two-dimensional mesoscale simulations of saturated pool boiling from rough surfaces. Part I: Bubble nucleation in a single cavity at low superheats, International Journal of Heat and Mass Transfer, 100 (2016) 927-937.

[38] Y. Michio, H. Kunio, M. Yasuo, U. Motokazu, Fundamental study of laminar film condensation heat transfer on a downward horizontal surface, International Journal of Heat and Mass Transfer, 28(10) (1985) 1937-1944.

[39] P.J. Berenson, Film-Boiling Heat Transfer From a Horizontal Surface, Journal of Heat Transfer, 83(3) (1961) 351-356. 